\title{
THE QUALITY OF DEATH AND DYING OF PATIENTS UNDER AT-HOME PALLIATIVE CARE, EVALUATED BY FAMILY AND FRIENDS OF THE PATIENT
}

\author{
Pawel Witt ${ }^{1} \odot$, Lukasz Czyzewski ${ }^{2}$ \\ ${ }^{1}$ Clinical Department of Anaesthesiology, Intensive Care and Postoperative Care, University Clinical Centre of the Medical University of Warsaw, \\ Children's Clinical Hospital in Warsaw, Poland \\ ${ }^{2}$ Department of Nephrology Nursing, Medical University of Warsaw, Poland
}

\begin{abstract}
INTRODUCTION: In Poland, there are no studies on the quality of dying and the moment of death. Studies described in the literature involve mostly the quality of life, care and treatment. Results of public surveys show that people have a lot of expectations of both the process and the moment of death. People pay attention to more and more widely known phenomenon of "good death and quality of dying", especially in patients whose prognosis is not positive and the causative treatment process was terminated. The main objective of the work was to research the quality of the process of dying, and the moment of death within patients in terminal state, that were under free, at-home palliative care.
\end{abstract}

MATERIAL AND METHODS: Study material was gathered with a validated, translated into polish language, anonymous sheet QODD - The Quality of Dying and Death. The group of recipients are families and friends who took care of a dying patient, who was taken care of by a Home Hospice Centre of the Congregation of Marian Fathers in Warsaw. Research material was being gathered since the beginning of 2016-2018. The original QODD questionnaire consists of 31 questions, although modified versions with 17 questions exist. The questionnaire with 31 questions was used in the research.

RESULTS: 150 questionnaires were collected (150 deceased people). The vast majority, i.e. 78 (52\%) of the group were women, the remaining percentage of $72(48 \%)$ were men. The patients very often controlled the situation they were in, were able to independently consume a meal. In most cases they did not feel dyspnoea, which is a measurable indicator of symptom control and improves the quality of life. Very frequently the patients were not at peace with death, but in most cases, they did not feel fear. Very frequently spent time with spouses, close ones and children. In most cases, the patients did not want to talk about the funeral ceremony but mostly they got to say goodbye to their loved ones. In most cases the patients never felt the need to hurry the process of death, but they also did not want to use life-supporting options. Regardless of their awareness of death the patients still had a purpose in life.

CONCLUSIONS: There are a lot of advantages coming from the research. They can be separated into two areas: Medical: improving the quality of life, ability to contract benefits as a result of an evaluation of the care process in at-home palliative care.

Research: comparison of the quality of dying in patients of at-home palliative care with stationary care, comparison of individual providers among each other, researching the quality of death within various illnesses, researching the quality of death and dying in children.

KEY WORDS: home palliative care; quality of death; dying in dignity; end of life

Disaster Emerg Med J 2019; 4(4): 137-141 


\section{INTRODUCTION}

In Poland, at-home palliative care is reimbursed for adult patients in cases of all tumours, illnesses caused by the human immunodeficiency virus, circulatory insufficiency, respiratory failure, repercussions of inflammatory neurological diseases, systemic lapses of the neurological system and decubitus ulcers [1]. At a home hospice, the patient is being provided with free nursing care no less frequently than two times a week, visits of psycho-oncologists and physiotherapists, social worker if needed. If the patient is interested, a clerical visit is also provided if needed [2]. The equipment needed for care and treatment of the patient is rented free of charge. Material assistance can also be provided in some cases. It is versatile and complex care directed at mitigating the symptoms of a progressive disease. In Poland, a view predominates that home hospice is just for patients in advanced stages of the disease, while in other countries it is being implemented within different stages of treatment, especially in patients with a serious prognosis [3].

\section{MATERIAL AND METHODS}

The study material was gathered with a validated, translated into polish language, anonymous sheet QODD - The Quality of Dying and Death. The group of recipients are families and friends who took care of a dying patient, who was taken care of by a Home Hospice Centre of the Congregation of Marian Fathers in Warsaw. Research material was being gathered since the beginning of 2016-2018. The original QODD questionnaire consists of 31 questions, although modified versions with 17 questions exist. The questionnaire with 31 questions was used in the research [4].

\section{Inclusion criteria}

The study group consists of deceased, adult patients (over 18) qualified for at-home palliative care contracted by the National Health Fund, regardless of the diagnosis. The respondents of a questionnaire survey are the caregivers of the deceased persons. It does not have to be an adult, because often the process of taking care of a terminally ill patient lays on children of the patient if they don't have a spouse or if the spouse is not able to resign from their career.

\section{Exclusion criteria}

Patients who remained unconscious at least 7 days before death were excluded from the research. Pa- tients who could not verbally communicate a month before death were not excluded. The second excluded group were patients who went to a stationary hospice or a hospital more than 7 days before death. The third excluded group were patients whose death occurred less than 7 days after admission to the home hospice.

\section{QODD — The Quality of Dying and Death}

Questions are divided into 3 groups:

- Has the incident occurred within the last 7 days of the patient's life, and if the patient could not communicate in the last 7 days/the last month of their life?

- Has the incident happened?

- Has the incident happened any time before death?

- Score 0-5:

$$
\begin{aligned}
& \circ \quad 0 \text { - never } \\
& \circ \quad 1 \text { - occasionally } \\
& \circ \quad 2 \text { - every once in a while } \\
& .3 \text { - frequently } \\
& .4 \text { - very frequently } \\
& .5 \text { - all the time }
\end{aligned}
$$

\section{Imprints}

There are two imprints included in the questionnaire: one applies to the person filling out the questionnaire, and the other one to the deceased patient. Applying to the person filling out the QUODD - sex, age, education, employment type (medical, non-medical), place of residence. Applying to the deceased patient who was cared for by the home hospice- sex, age, education, place of residence, type of illness (cancerous, non-cancerous), time spent in care of the home hospice (in weeks), time from patients death to filling out the questionnaire (in weeks). Questions regarding the patient are grouped into sections: symptoms and personal control, preparing for death, moment of death, course of the disease, connection with family and an overall attitude. For 28 out of 31 questions the respondent answers in $0-5$ scale, where 0 stands for never; 1 - occasionally; 2 - every once in a while; 3 - frequently; 4 - very frequently; 5 - all the time. The last 3 are yes or no questions.

Symptoms and personal control:

- How often did the patient feel pain?

- How often did the patient have control over what is happening?

- How often did the patient have a chance to independently ingest food? 
- How often did the patient control emiction and defecation?

- How often did the patient feel dyspnoea?

- How often did the patient have enough energy? Preparation for death:

- Did the behaviour of the patient show that the patient was at peace with death?

- Did the patient feel the fear of death?

- Was the patient concerned about the family's fear?

- Did the patient have any financial obligations related to the treatment?

- Did the patient have a clerical visit?

- Did the patient talk about the funeral ceremony?

- Did the patient take part in funeral preparations?

- Did the patient say their goodbyes to the family?

- Did the patient take part in important events?

- Did the patient get rid of negative feelings?

Moment of death (yes or no):

- Did the patient die at home?

- Were the patient's loved ones present in the moment of death?

- Was the patient aware in the past minutes of life?

- Family

- Did the patient spend time with their spouse/partner?

- Did the patient spend time with their kids?

- Did the patient spend time with extended family and/or friends?

- Did the patient spend time alone?

- Did the patient spend time with animals?

The course of medical care:

- Did the patient have conversations about end of life with the doctor

- Did the patient feel the need to expedite the death?

- Did the patient feel the need to or wanted to avoid life-supporting treatments?

Overall attitude:

- Did the patient smile and laugh?

- Did the patient express their feelings?

- Did the patient have a goal in life

- Did the patient have high self-esteem and did they respect themselves?

\section{Statistical analysis}

In order to answer the research questions, statistical analyses were carried out using the TIBCO Statistica 13.3 software. With its use, basic descriptive statistics were analysed along with Shapiro-Wilk tests as well as correlation analysis using Pearson's $r$ and Spearman's $\rho$, Student's t-test analysis for independent samples, one-way analysis of variance in the intergroup diagram. The classic threshold $\alpha=0.05$ was considered the level of significance.

\section{RESULTS}

150 questionnaires were collected (150 deceased people). The majority, i.e. 78 (52\%) of the group were women, the remaining percentage of $72(48 \%)$ were men. Most of the respondents are women between the age of 30 and 50. Higher education dominates. Most of the people perform a non-medical profession and live in a city. Within patients in palliative care, men with secondary education and living in the city were dominating. Within the deceased, the diagnosis of cancer prevails. The patients very often controlled the situation they were in, were able to independently consume a meal. In most cases, they did not feel dyspnoea, which is a measurable indicator of symptom control and improves the quality of life. Very frequently the patients were not at peace with death, but in most cases, they did not feel fear. Very frequently spent time with spouses, close ones and children. In most cases the patients did not want to talk about the funeral ceremony but mostly they got to say goodbye to their loved ones. In most cases the patients never felt the need to hurry the process of death, but they also did not want to use life-supporting options. Regardless of their awareness of death the patients still had a purpose in life.

\section{Relationship between the quality of death and dying and the patient's age}

It was decided to verify the research hypothesis that there is a relationship between the quality of death in dying patients under palliative home care and their age. To this end, a number of correlation analyses were performed with the Pearson's $r$ ratio, comparing the patient's age and the results of individual QODD subscales: Symptoms and personal control, Family, Moment of death, Course of medical care, Preparation for death, Holistic approach.

It turned out that there is a statistically significant, weak, negative correlation between age and the results of the Symptoms and Personal Control and Family subscales. In addition, there is a statistically significant, weak, positive correlation between age and the results of the Preparation for Death subscale.

This means that older patients present worse quality of death and dying in terms of disease symp- 
toms and personal control, as well as family relationships while showing better preparation for death.

In the remaining subscales, no statistically significant correlation with age was noted. This means that the quality of death and dying in this regard was not related to the patient's age. The results are shown in Table 1.

\section{The relationship between the quality of death and dying and the time spent in the home hospice}

It was decided to verify the research hypothesis that there is a relationship between the quality of death in dying patients under palliative home care and the time spent in the home hospice. To this end, a number of correlation analyses were performed with the Spearmann coefficient, comparing the time spent in the home hospice (in weeks) and the results of individual QODD subscales: Symptoms and personal control, Family, Moment of death, Course of medical care, Preparation for death, Holistic approach.

In none of the subscales there were statistically significant correlations with the time spent in the home hospice. This means that the quality of death and dying was not linked to the time spent in the care of the home hospice. The results are shown in Table 2.

\section{Quality of death and dying depending on gender}

Subsequently, it was decided to answer the research question of whether men and women under palliative home care differ from each other in quality of death and dying. For this purpose, both sexes were

\begin{tabular}{|c|c|c|}
\hline & & Age \\
\hline \multirow{2}{*}{$\begin{array}{l}\text { Symptoms and } \\
\text { personal control }\end{array}$} & r Pearsona & -0.184 \\
\hline & $P$ & 0.024 \\
\hline \multirow[t]{2}{*}{ Family } & r Pearsona & -0.206 \\
\hline & $\mathrm{P}$ & 0.012 \\
\hline \multirow[t]{2}{*}{ Moment of death } & r Pearsona & -0.101 \\
\hline & $P$ & 0.217 \\
\hline \multirow{2}{*}{$\begin{array}{l}\text { The course of medical } \\
\text { care }\end{array}$} & r Pearsona & -0.008 \\
\hline & $P$ & 0.923 \\
\hline \multirow[t]{2}{*}{ Preparation for death } & r Pearsona & 0.176 \\
\hline & $P$ & 0.031 \\
\hline \multirow[t]{2}{*}{ Holistic approach } & r Pearsona & -0.100 \\
\hline & $P$ & 0.223 \\
\hline
\end{tabular}

compared in terms of the results of individual QODD subscales: Symptoms and personal control, Family, Moment of death, Course of medical care, Preparation for death, Holistic approach. Student's t-tests were carried out for independent tests.

It turned out that men in the study presented significantly higher results for the Family subscale than women - it means that the quality of death and dying in men in this respect was significantly better than in women. The strength of the observed relationship, measured by Cohen's d factor, proved to be high.

However, as regards the remaining QODD subscales, the quality of death and dying did not differ significantly between the two sexes. The results are shown in Table 3.

\section{DISCUSSION}

In recent years, the problem of the process of $d y$ ing and its quality has become a subject of particular interest not only to representatives of medical sciences, philosophers, psychologists, but also to all people. Many people have begun to ask themselves whether a person who suffers must suffer [5]. The problem of the quality of dying is, good death, the will of the end of life is more emphasized by foreign than Polish researchers [6]. Although palliative care in Poland is flourishing, death itself is still marginalized. Perhaps this is due to the author's own experience that modern education of medical staff treats the patient's

\begin{tabular}{|c|c|c|}
\hline & & $\begin{array}{l}\text { Time spent in the } \\
\text { home hospice }\end{array}$ \\
\hline \multirow{2}{*}{$\begin{array}{l}\text { Symptoms and } \\
\text { personal control }\end{array}$} & $\rho$ Spearmana & -0.001 \\
\hline & $P$ & 0.988 \\
\hline \multirow[t]{2}{*}{ Family } & $\rho$ Spearmana & 0.014 \\
\hline & $P$ & 0.862 \\
\hline \multirow[t]{2}{*}{ Moment of death } & $\rho$ Spearmana & 0.013 \\
\hline & $P$ & 0.878 \\
\hline \multirow{2}{*}{$\begin{array}{l}\text { The course of medical } \\
\text { care }\end{array}$} & $\rho$ Spearmana & 0.119 \\
\hline & $P$ & 0.147 \\
\hline \multirow[t]{2}{*}{ Preparation for death } & $\rho$ Spearmana & 0.096 \\
\hline & $P$ & 0.242 \\
\hline \multirow[t]{2}{*}{ Holistic approach } & $\rho$ Spearmana & 0.032 \\
\hline & $P$ & 0.702 \\
\hline
\end{tabular}


Table 3. Quality of death and dying by gender

\begin{tabular}{|c|c|c|c|c|c|c|c|c|c|}
\hline & \multicolumn{2}{|c|}{ Women $(n=78)$} & \multicolumn{2}{|c|}{ Men $(n=72)$} & \multirow[b]{2}{*}{$t$} & \multirow[b]{2}{*}{$\mathrm{p}$} & \multicolumn{2}{|c|}{$95 \% \mathrm{Cl}$} & \multirow[b]{2}{*}{ d Cohena } \\
\hline & M & SD & $M$ & SD & & & LL & UL & \\
\hline Symptoms and personal control & 45.90 & 16.89 & 46.53 & 18.13 & -0.22 & 0.826 & -6.30 & 5.04 & 0.05 \\
\hline Family & 43.33 & 13.45 & 50.67 & 13.36 & -3.35 & 0.001 & -11.66 & -3.00 & 0.73 \\
\hline Moment of death & 57.26 & 33.93 & 64.35 & 29.78 & -1.35 & 0.178 & -17.37 & 3.20 & 0.29 \\
\hline The course of medical care & 71.71 & 23.96 & 77.59 & 20.21 & -1.62 & 0.108 & -13.02 & 1.25 & 0.34 \\
\hline Preparation for death & 41.44 & 14.24 & 39.69 & 12.23 & 0.80 & 0.425 & -2.53 & 6.01 & 0.17 \\
\hline Holistic approach & 59.81 & 18.61 & 57.08 & 17.70 & 0.92 & 0.361 & -3.13 & 8.58 & 0.20 \\
\hline
\end{tabular}

death as a failure. In the age of advanced technology the death limit is prolonged. However, the moment comes that it cannot be remedied [1]. The author's research coincides with international literature. Home palliative care, i.e. the one most comfortable for the patient, reduces pain, shortness of breath, reduces overwhelming pain [3]. It often allows one to finish life as if the patient wanted it [7]. It allows one to talk about death, the very process of passage, funeral. It allows to spend time with the loved ones, but also with pets. patients dying with dignity paradoxically improve their quality of life that is left to them. The family, palliative care team, allows to experience the loss calmly and consciously - by continuing care after the patient's death [8].

There are a lot of advantages coming from the research. They can be separated into two areas:

- medical: improving the quality of life, ability to contract benefits as a result of the evaluation of the care process in at-home palliative care,

- research: comparison of the quality of dying in patients of at-home palliative care with stationary care, comparison of individual providers among each other, researching the quality of death within various illnesses, researching the quality of death and dying in children.
Conflict of interests: The authors declare that they have no conflicts of interests. None of the authors involved in this study have any financial relationship.

Source of support: No sources of financial and material support to be declared.

\section{REFERENCES}

1. Ciałkowska-Rysz A, Dzierżanowski T. Palliative medicine. Termedia, Poznań 2019.

2. Buczkowski K, Krajnik M. Palliative care. Wydawnictwo Lekarskie PZWL, Warszawa 2009.

3. de Walden-Gałuszko K, Ciałkowska-Rysz A. Palliative medicine. Wydawnictwo Lekarskie PZWL, Warszawa 2015.

4. Downey L, Curtis JR, Lafferty WE, et al. The Quality of Dying and Death Questionnaire (QODD): empirical domains and theoretical perspectives. J Pain Symptom Manage. 2010; 39(1): 9-22, doi: 10.1016/j. jpainsymman.2009.05.012, indexed in Pubmed: 19782530.

5. Scheller M. The philosophy of death from Anaksymander to Adorno. WAM, Kraków 2008.

6. Fassbender K, Fainsinger RL, Carson M, et al. Cost trajectories at the end of life: the Canadian experience. J Pain Symptom Manage. 2009; 38(1): 75-80, doi: 10.1016/j.jpainsymman.2009.04.007, indexed in Pubmed: 19615630.

7. Grzywa A. Old age, dying and death. How to deal with it? Wydawnictwo Czelej, Lublin 2016.

8. Guzowski A, Krajewska-Kułak E, Kułak W, et al. Contemporary attitudes towards death and dying. Med Paliat. 2013; 5. 